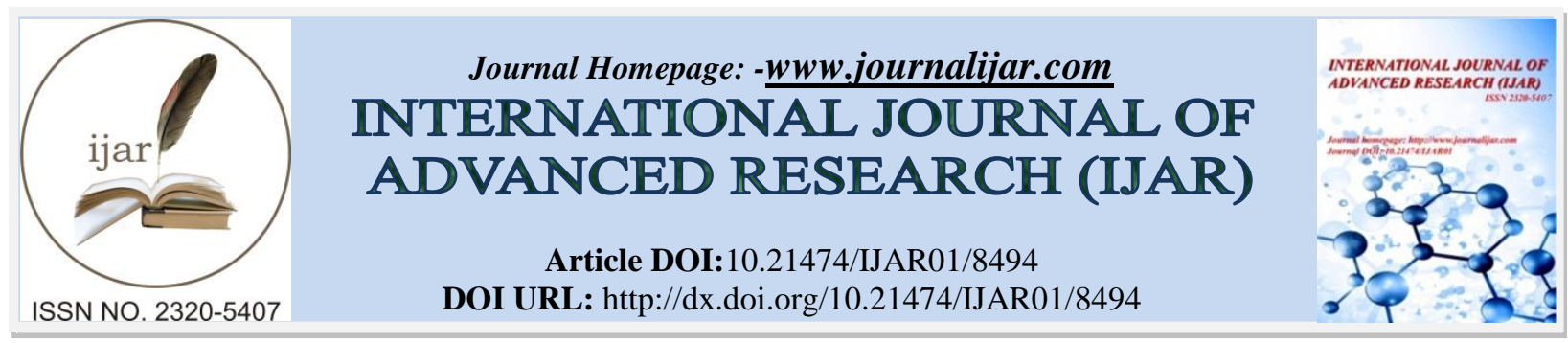

RESEARCH ARTICLE

\title{
RETINAL NERVE FIBRE LAYER THICKNESS AND OPTIC NERVE HEAD SIZE MEASURED IN MYOPES BY OCT: DOES MAGNIFICATION PLAY A ROLE?.
}

Kaavya Hanuraj Kolalapudi, K.Venkateswarlu and V A N P Kumari Oruganti. Junior Resident, Ophthalmology, Andhra Medical College, Visakhapatnam.

\section{Manuscript Info}

\section{Manuscript History}

Received: 04 December 2018

Final Accepted: 06 January 2019

Published: February 2019

Key words:-

Myopes, RNFL thickness, OCT.

\section{Abstract}

Purpose:To study RNFL thickness and optic nerve head (ONH) size in myopic eyes with and without magnification adjustments by optical coherence tomography and compare with magnification-adjusted OCT measurements of emmetropic control eyes.

Methods: In a cross-sectional study, RNFL thickness (global circle and quadrants) andONH size (disc and rim areas) were measured in eyes of 25 myopic participants. Magnification adjusted measurements taken in myopes were then compared with adjusted measurements taken in 25 emmetropic controls.

Results: Comparison of magnification-adjusted measurements between myopesandemmetropic controls showed that myopic eyes had significantly thicker globaland temporal RNFLs, thinner nasal RNFL and larger disc and rim areas. Superior and inferior RNFL thickness measurements did not differ significantly between the two groups.

Conclusion: Magnification-adjusted OCT measurements show global and temporal RNFL thicknesses and $\mathrm{ONH}$ size increase in myopic eyes.

Copy Right, IJAR, 2019,. All rights reserved.

\section{Introduction:-}

Myopia is the most common refractive error worldwide. Its prevalence in adults is reported to be about $30 \%$ worldwide.Myopia has been widely reported to affect the size and shape of the optic disc and peripapillary retinal nerve fiber layer. Thorough and accurate understanding of the relationship between myopia and these structures is important, as there is higher risk of glaucoma in myopic individuals compared to non-myopic individuals

\section{Aim of the study:}

To study retinal nerve fiber layer(RNFL) thickness and optic nerve head (ONH) size in high myopic eyes with and without magnification adjustments by optical coherence tomography and compare with magnification-adjusted OCT measurements of emmetropic control eyes.

\section{Materials and methods:-}

\section{Methodology:}

It is a hospital based case-control study which was conducted in the period of January 2017 to March 2017at Govt. Regional Eye Hospital Visakhapatnam. The study was done among 50 patients.

Corresponding Author:-Kaavya HanurajKolalapudi.

Address:-Junior Resident, Ophthalmology, Andhra Medical College, Visakhapatnam. 


\section{Inclusion Criteria:}

Patients attending GREH with refractive power of spherical equivalent > -6D for test group i.ehighmyopic group. Patients attending GREH with refractive error of spherical equivalent of $0.50 \mathrm{D}$ to $+0.50 \mathrm{D}$ for control group

\section{Exclusion criteria:}

Patients with intra ocular pressure of more than

$21 \mathrm{~mm}$ of $\mathrm{Hg}$

Patients with hazy media

Presence of any optic nerve disease, peripapillary area atrophy, disc abnormalities

History of intra cranial diseases

History of usage of any medications like steroids etc

History of previous ocular surgery

\section{Procedure:}

Patients attending to the OPD were examined under slit lamp. The refractive error of the patients was measured by autorefractometer andor cycloplegicretinoscopy, and then subjective verification was done for these patients.

Depending upon the refractive error they were divided into two groups: the test group and the control group.IOP was measured by applanationtonometer.In both the groupsindividually axial length was measured for each patient by A Scan.

The OCT examinations were done by CIRRHUS HD OCT, after the instillation of mydriatic, in dim light.The optic nerve head(ONH) and retinal nerve fiber layer thickness(RNFL) parameters were measured by CIRRHUS HD OCT with the optic disc cube 200x 200 scan protocol. The values were then adjusted for magnification.

To determine the actual size of an object on the fundus of the living eye, Littmann recommended adjusting the size of a retinal feature observed by fundus photography.

The relationship between the measurements obtained by an imaging system and actual fundus dimension measurements can be expressed as

$\mathrm{t}=\mathbf{p} \times \mathbf{q} \times \mathbf{s}^{1}$,

wheret is the actual fundus dimension,

$\mathrm{p}$ is the magnification factor for the imaging system,

$\mathrm{q}$ is the magnification factor related to the eye and

$\mathrm{s}$ is the measurement obtained by an imaging system

Kang et al adjusted the Littmann formula of the thickness $\mathrm{t}=\mathrm{p} \times \mathrm{q} \mathrm{x} \mathrm{s}$ for area into $\mathrm{t}^{2}=\mathrm{p}^{2} \mathrm{x}^{2} \mathrm{x} \mathrm{s}^{2}$ which was used for optic nerve head to calculate the disc and rim $\operatorname{area}^{2}$

1. The OCT system has a p-value of $3.382^{2}$,

2. The formula for obtaining theq-value(magnification factor)for the eye is $\mathrm{q}=0.01306 \mathrm{x}(\mathrm{AL}-1.82)^{2}$.

3. The recommended magnification adjustments for RNFL thickness and disc and rim area were given in Table:1

Table 1:-

\begin{tabular}{|l|l|}
\hline RNFL thickness & $\begin{array}{l}3.382 \times[0.01306 \times(\mathrm{AL}-1.82)] \times \text { measured RNFL } \\
\text { thickness }\end{array}$ \\
\hline Disc and rim area & $\begin{array}{l}(3.382)^{2} \times\left[(0.01306 \times(\mathrm{AL}-1.82))^{2}\right] \times \\
(\text { measured disc area })^{2}\end{array}$ \\
\hline
\end{tabular}

Statistical analysis:-

Data was analysedstatistically.For the purposes of this report, only scans of the eyewith signal strengths greater than 7 were used in analysis.For the RNFL and ONH comparision, Paired t tests were used. 


\section{Results:-}

There was no significant statistical difference between age of the test and control groups. There was significant difference between spherical equivalence and axial length between the two groups(Table -2)

OCT measurements after magnification adjustments in high myopic eyes and control eyes were greater than those without magnification adjustment in the two groups $(\mathrm{p}<0.001)($ TABLE -3$)$

Table 2:-

\begin{tabular}{|c|c|c|c|}
\hline Age & $\begin{array}{l}36.55 \pm 9.44 \text { years } \\
(22-41)\end{array}$ & $\begin{array}{l}34.82 \pm 8.87 \text { years } \\
(20-45)\end{array}$ & 0.2091 \\
\hline Spherical equivalence & $\begin{array}{l}-11.56 \pm 0.64 D \\
(-6.0 \text { to }-18)\end{array}$ & $\begin{array}{l}-0.65 \pm 0.41 \mathrm{D}(-0.50 \text { to } \\
+0.50)\end{array}$ & $<0.001$ \\
\hline Axial length & $\begin{array}{l}26.17 \pm 1.2 \\
(24.0-29.5)\end{array}$ & $\begin{array}{l}22.16 \pm 0.82 \mathrm{~mm} \\
(21.95-23.40)\end{array}$ & $<0.001$ \\
\hline
\end{tabular}

RETINAL NERVE FIBER LAYER THICKNESS

\begin{tabular}{|l|l|l|l|}
\hline Myopic eyes & Before magnification & After magnification & P value \\
\hline Global & $100.76 \pm 10.68$ & $112.85 \pm 11.43$ & $<0.001$ \\
\hline Superior & $125.1 \pm 17.3$ & $140.16 \pm 17.5$ & $<0.001$ \\
\hline Inferior & $120.2 \pm 20.1$ & & $<0.001$ \\
\hline
\end{tabular}




\begin{tabular}{|l|l|l|l|}
\hline Nasal & $67.8 \pm 6.45$ & $72.9 \pm 7.06$ & $<0.001$ \\
\hline Temporal & $65.8 \pm 16.4$ & $76.8 \pm 17.9$ & $<0.001$ \\
\hline
\end{tabular}

\section{Table 3:-}

Magnification-adjusted OCT measurements of the global and temporal RNFLs were significantly thicker in myopic eyes than in control eyes ( $p<0.001$ ), nasal RNFL was significantly thinner in myopic eyes than in control eyes $(\mathrm{p}<0.001)$. Superior and inferior RNFL thickness measurements did not differ significantly between the two groups $(\mathrm{p}>0.001)$. (Table-4)

Disc and rim areas were significantly larger in myopic eyes than in control eyes $(\mathrm{p}<0.001)$. (Table -5$)$

\section{Table 4:-}

\section{MAGNIFICATION ADJUSTED RETINAL NERVE FIBER LAYER}

\section{THICKNESS}

\begin{tabular}{|l|l|l|l|}
\hline & MYOPIC EYES & CONTROL EYES & P value \\
\hline Global & $112.85 \pm 11.43$ & $107.27 \pm 11.01$ & $<0.001$ \\
\hline Superior & $140.16 \pm 17.5$ & $137.45 \pm 15.4$ & 0.68 \\
\hline Inferior & $132.8 \pm 21.1$ & $135.9 \pm 22.4$ & 0.62 \\
\hline Nasal & $72.9 \pm 7.06$ & $78.3 \pm 12.3$ & $<0.001$ \\
\hline Temporal & $76.8 \pm 17.9$ & $65.6 \pm 18.32$ & $<0.001$ \\
\hline
\end{tabular}

Table 5:-

\begin{tabular}{|l|l|l|l|l|}
\hline MYOPES & DISC AREA & $2.54 \pm 0.65$ & $3.20 \pm 0.60$ & $<0.001$ \\
\hline CONTROL & DISC AREA & $1.97 \pm 0.23$ & $2.71 \pm 0.28$ & \\
\hline MYOPES & RIM AREA & $1.81 \pm 0.50$ & $2.35 \pm 0.79$ & $<0.001$ \\
& & & & \\
\hline CONTROL & RIM AREA & $1.47 \pm 0.19$ & $2.01 \pm 0.44$ & $<0.001$ \\
\hline
\end{tabular}




\section{Discussion:-}

Certain anatomical changes that occur in longer axial length eyes such as globe elongation, scleral widening, and subsequently enlargement of the lamina cribrosa, result in larger disc areas in such eyes. The use of magnificationadjustment can correct disc and rim areas measurements in those eyes

In this study after magnification the disc and rim areas of optic nerve head were significantly larger in highmyopes than in control eyes. In a study done by Sheng yaohsu et al, OCT measurements with magnification adjustment found that highly myopic eyes have larger ONH size than in normal eyes. This study shows that magnification adjusted RNFL thickness were significantly thicker in global and temporal quadrants in myopic eyes compared to non-myopic eyes .There was no significant difference between superior and inferior RNFL thickness between the two groups.

In highly myopic eyes, only the nasal nerve fibre layer is subnormal, whereas the superior and inferior RNFL thicknesses are normal. In a study conducted by Lueng et al, without magnification adjustment, they reported that highly myopic eyes have significantly lower RNFL thickness globally and temporally ${ }^{4}$.

In a study done by Sheng Yaohsu et al, OCT measurements with magnification adjustment found that highly myopic eyes have thicker temporal and global RNFL thicknesses than in control eyes ${ }^{3}$. In another study by Hyun Bae et al, disc area and RNFL thickness decreased in high myopic eyes, they increased after adjustment for the magnification effect ${ }^{5}$ Based on this, the ONH size and RNFL measurements were influenced by the magnification effect. Hence, prior to diagnosis of glaucomatous or non-glaucomatous optic atrophy in highly myopic patients where there is thinning of RNFL thickness, the magnification effect should be considered.

\section{Conclusion:-}

Magnification-adjusted OCT measurements show:

1. Increased RNFL thickness in global and temporal quadrants in high myopic eyes

2. Increased Optic nerve head size in high myopic eyes.

3. Magnification adjusted parameters will be helpfull in accurate evaluation in order to avoid misdiagnosis of glaucoma in high myopic eyes.

\section{References:-}

1. Littmann H. Determination of the real size of anobject on the fundus of the living eye (in German). KlinMonatsblAugenheilkd. 1982;180:286-9.

2. Leung CK, Cheng AC, Chong KK, et al. Optic disc measurements in myopia with optical coherence tomography and confocal scanning laser ophthalmoscopy. InvestigOphthalmol Vis Sci.2007;48:3178-83

3. Sheng-Yao Hsu Md et al, Retinal nerve fibre layer thickness and optic nerve head size measured in high myopes by optical coherence tomography , ClinExpOptom 2013; 96: 373- 378

4. Christopher Kai-Shun Leung et al, Retinal Nerve Fiber Layer Measurements in Myopia: An Optical Coherence Tomography Study, Investigative Ophthalmology \& Visual Science, December 2006, Vol. 47, No. 12

5. Seok Hyun Bae et al, Influence of Myopia on Size of Optic Nerve Head and Retinal Nerve Fiber Layer Thickness Measured by Spectral Domain Optical Coherence Tomography, Korean J Ophthalmol 2016;30(5):335-343

6. HebaRadiAttaAllah et al, Evaluation of Optic Nerve Head Parameters and Retinal Nerve Fiber Layer Thickness in Axial Myopia Using SD OCT, Ophthalmol Ther,2017

7. Jonas JB, Budde WM, Panda Jonas S. Ophthalmoscopic evaluation of the optic nerve head. Surv-Ophthalmol. 1999;43:293-320.

8. Vessani RM, Moritz R, Batis L, et al. Comparison of quantitative imaging devices and subjective optic nerve head assessment by general ophthalmologists to differentiate normal from glaucomatous eyes.J Glaucoma. 2009;18:253-61.

9. DeLeon Ortega JE, Sakata LM, Kakati B, et al. Effect of glaucomatous damage on repeatability of confocal scanning laser ophthalmoscope, scanning laser polarimetry, and optical coherence tomography InvestigOphthalmol Vis Sci. 2007;48:1156-63.

10. Samarawickrama C, Hong T, Jonas JB, Mitchell P.The measurement of normal optic nerve head parameters. SurvOphthalmol. 2012;57(4):317-36. 
11. Alencar LM, Zangwill LM, Weinreb RN, etal.Agreement for detecting glaucoma progression with the GDx guided progression analysis, automated perimetry, and optic disc photography. Ophthalmology. 2010;117:46270.

12. Tay E, Seah SK, Chan SP, et al. Optic disk ovality as an index of tilt and its relationship to myopia and perimetry. Am J Ophthalmol. 2005;139:247-52.

13. Jonas JB. Optic disk size correlated with refractive error. Am J Ophthalmol. 2005;139:346-8.

14. Shoji T, Sato H, Ishida M, Takeuchi M, Chihara E. Assessment of glaucomatous changes in subjects with high myopia using spectral domain optical coherence tomography. InvestigOphthalmol Vis Sci. 2011;52(2):1098102.

15. Littmann H. Determination of the real size of an object on the fundus of the living eye (in German). KlinMonatsblAugenheilkd. 1982;180:286-9.

16. Leung CK, Cheng AC, Chong KK, et al. Optic disc measurements in myopia with optical coherence tomography and confocal scanning laser ophthalmoscopy.InvestigOphthalmol Vis Sci. 2007;48:3178-83.

17. Bennett AG, Rudnicka AR, Edgar DF. Improvements on Littmann's method of determining the size of retinal features by fundus photography. Graefes Arch ClinExpOphthalmol. 1994;232:361-7.

18. Feuer WJ, Budenz DL, Anderson DR, et al. Topographic differences in the age-related changes in the retinal nerve fiber layer of normal eyes measured by Stratus optical coherence tomography.J Glaucoma. 2011;20:1338.

19. Kang SH, Hong SW, Im SK, Lee SH, Ahn MD. Effect of myopia on the thickness of the retinal nerve fiber layer measured by Cirrus HD optical coherence tomography. InvestigOphthalmol Vis Sci.2010;51:4075-83. 